\title{
Exploring the Relationships between Hemoglobin, the Endothelium and Vascular Health in Patients with Chronic Kidney Disease
}

\author{
Catherine Weber $^{\mathrm{a}}$ Mhairi Sigrist $^{\mathrm{a}}$ Alexandra Romann $^{\mathrm{b}}$ \\ Beth A. Whalen ${ }^{c}$ Adeera Levin ${ }^{a}$ \\ a Division of Nephrology, Department of Medicine, University of British Columbia, \\ bProvincial Renal Agency, and 'James Hogg iCAPTURE Center for Cardiovascular and \\ Pulmonary Research, University of British Columbia, St. Paul's Hospital, Vancouver, B.C., \\ Canada
}

\section{Key Words}

Anemia $\cdot$ Biomarkers $\cdot$ Chronic kidney disease $\cdot$ Endothelial dysfunction $\cdot$ Pulse wave velocity . Vascular disease

\begin{abstract}
Background/Aims: The ideal hemoglobin target in chronic kidney disease remains unknown. Ultimately, individualized targets may depend upon the properties of the patient's endothelial and vascular milieu, and thus the complex relationships between these factors need to be further explored. Methods: Forty-six patients with a glomerular filtration rate (GFR) $<30 \mathrm{ml} /$ $\mathrm{min} / 1.73 \mathrm{~m}^{2}$ or on renal replacement therapy underwent measurement of hemoglobin, endothelial microparticles (EMPs) and aortic pulse wave velocity (PWV) at 0, 3 and 6 months. In addition, a number of inflammatory, cardiac and vascular biomarkers were measured at baseline. Results: No correlation was observed between baseline values of PWV and EMPs, PWV and hemoglobin, or hemoglobin and EMPs in the overall cohort. When stratified by CKD status, a positive correlation was observed between PWV and EMP CD41-/CD144+ in patients with GFR $<30$ $\mathrm{ml} / \mathrm{min} / 1.73 \mathrm{~m}^{2}$ only $(\mathrm{r}=0.54, \mathrm{p}=0.01)$. Asymmetric dimethylarginine correlated with baseline PWV $(r=0.27, p=0.07)$, and remained significantly correlated with the 3-and 6-month PWV measurement. Conclusions: In this small heterogeneous cohort of dialysis and non-dialysis patients, we were unable to describe a physiologic link between anemia, endothelial dysfunction and arterial stiffness.

Copyright $\odot 2011$ S. Karger AG, Basel
\end{abstract}




\section{Introduction}

Anemia related to chronic kidney disease (CKD) may contribute to endothelial dysfunction through a decrease in shear stress, as physiologic laminar fluid shear stress is crucial for normal vascular function and structure $[1,2]$. Anemia in CKD patients is also associated with arterial stiffness [3]. However, despite the potential 'endothelial benefit' of increasing hemoglobin in CKD patients, hemoglobin normalization is associated with a poor clinical outcome [4-7].

Endothelial dysfunction has been shown to be an important component of vascular disease in CKD patients $[8,9]$. Endothelial microparticles (EMPs) are small $(<1 \mu \mathrm{m}$ in diameter), non-nucleated phospholipid vesicles shed from the endothelial cell membrane in states of endothelial activation or apoptosis and express on their cell surface various antigens specific to the state of their parental endothelial cell $[10,11]$. Given technological advances, we are now able to measure EMPs and thus 'quantify' the phenomenon of endothelial dysfunction [12].

EMPs have been demonstrated to be elevated in a variety of clinical states characterized by vascular disease and have been identified in those with CKD [13-18]. EMPs have been shown to correlate with indices of arterial stiffness in hypertension and end-stage renal disease, suggesting a possible role of EMPs in the vascular disease process $[18,19]$.

We sought to further explore the relationship between EMPs, hemoglobin and arterial stiffness (measured by aortic pulse wave velocity, PWV) as a preliminary step in approaching the clinical dilemma of anemia management and endothelial health in CKD patients.

\section{Study Design and Methods}

This prospective observational study was undertaken at a single tertiary-care institution, St. Paul's Hospital, between January 2008 and January 2009. The study measured both PWV and EMP at 0, 3 and 6 months. At baseline, blood tests for conventional tests and specific biomarkers were included. All subjects were studied without discontinuation of any medication.

We included patients on dialysis (conventional hemodialysis, HD, or peritoneal dialysis, $\mathrm{PD})$ and those not on dialysis with estimated glomerular filtration rate (eGFR) $<30 \mathrm{ml} /$ $\mathrm{min} / 1.73 \mathrm{~m}^{2}$ for $>6$ months. Those on dialysis required stable access for 3 months and all required stable hemoglobin for 2 months $( \pm 10 \mathrm{~g} / \mathrm{l})$. Exclusion criteria included a known dysrhythmia, dementia and clinical inability to comply with testing. Subjects with previous renal transplant were also excluded. This study received institutional ethics approval and adhered to the Declaration of Helsinki. All patients provided informed consent.

\section{Clinical and Laboratory Variables}

Data collection included demographic and clinical variables, and 'usual' conventional blood work values (i.e. white blood cell count, WBC, hemoglobin, iron saturation, calcium, phosphate, parathyroid hormone, albumin, $\mathrm{HbA}_{1 \mathrm{C}}$, total cholesterol, triglycerides, low-density lipoprotein and high-density lipoprotein). In order to minimize blood drawing, the blood work values were taken from the patient records closest to the date of the first PWV measurement ( \pm 3 months).

At baseline, each subject had the following biomarkers measured: pro-inflammatory interleukin (IL)-18 (MBL, Nagoya, Japan; detection limit: 12.5 pg/ml), anti-inflammatory IL-10 (R\&D Systems, Minneapolis, Minn., USA; detection limit: $3.9 \mathrm{pg} / \mathrm{ml}$ ), calcification inhibitor fetuin A (Alpco Diagnostics, Salem, N.H., USA; detection limit: $0.05 \mathrm{~g} / \mathrm{l}$ ), endogenous competitive inhibitor of nitric oxide synthase asymmetric dimethylarginine (ADMA; Alpco Diagnostics; measured by competitive ELISA method; detection limit: $0.05 \mu \mathrm{mol} / \mathrm{l})$, highly sen- 
sitive C-reactive protein (hs-CRP; Siemens BN-II nephelometer CardioPhase hsCRP method; detection limit: $0.175 \mathrm{mg} / \mathrm{l}$ ), B-natriuretic peptide (Siemens Centaur immunoassay analyzer; detection limit: $2 \mathrm{pg} / \mathrm{ml}$ ) and troponin I (Siemens Centaur immunoassay analyzer; detection limit: $0.02 \mu \mathrm{g} / \mathrm{l})$. These biomarkers were selected on the basis of assay robustness, linkage to known pathophysiologial processes presumed to be important in structural and functional vascular changes, and known association in CKD populations to portend increased morbidity and mortality. HD patients had blood work drawn prior to a mid-week dialysis session, and $\mathrm{CKD}$ and $\mathrm{PD}$ patients had blood sampled during routine outpatient clinic visits.

\section{Endothelial Microparticles}

We measured the following EMPs: CD41-/CD144+, a specific EMP, CD41-/CD144+/ CD31+, a marker of endothelial apoptosis, and CD62E+, a marker of endothelial activation.

Preparation of Platelet-Free Plasma for EMP Analysis. Within $1 \mathrm{~h}$ of collection, citrated blood was spun at $1,500 \mathrm{~g}$ for $15 \mathrm{~min}$ at room temperature. The platelet-poor plasma was carefully removed and further spun at $12,700 \mathrm{~g}$ for $10 \mathrm{~min}$ at room temperature to obtain platelet-free plasma. The platelet-free plasma was stored at $-80^{\circ} \mathrm{C}$ for future flow-cytometric characterization and enumeration of EMP subpopulations.

Flow-Cytometric Characterization and Enumeration of EMP Subpopulations. Undiluted platelet-free plasma $(100 \mu \mathrm{l})$ was incubated at room temperature for $30 \mathrm{~min}$ with the following antibodies or their respective isotype controls: CD31-FITC, clone WM59 (BD Bioscience, catalogue No. 555445), CD144-PE, clone TEA1/31 (Beckman Coulter, catalogue No. A07481), CD41-PC5, clone P2 (Beckman Coulter, catalogue No. 6607116), $\operatorname{IgG}_{1}$-FITC (Dako, cata-

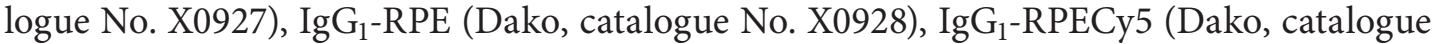
No. X0955) and CD62E-PE, clone 68-5H11 (BD Bioscience, catalogue No. 551145). Following incubation with antibodies, flow count beads $(100 \mu \mathrm{l}$; Beckman Coulter, catalogue No. 7547053) were added to each sample and analysis immediately performed using a MoFlo high-speed cell sorter (Beckman Coulter). A forward and side scatter dot plot was used to determine analysis regions while running microspheres of known size $(0.5$ and $1.0 \mu \mathrm{m})$. EMPs were defined as events $<1 \mu \mathrm{m}$ in size and expressing the antigens CD41-/CD144+. EMPs were further investigated for their CD31 expression, or lack thereof. Separately, CD62E+ MPs were quantified. The number of EMPs per microliter was calculated as per the manufacturer specifications: absolute EMP count $(\mathrm{n} / \mu \mathrm{l})=$ (total number of MPs counted/ total number of beads counted) $\times$ flow count beads assayed per concentration. Flow Check high-intensity alignment grade 1.0 - and $0.5-\mu \mathrm{m}$ particles were obtained from Polysciences (catalogue Nos. 23517-10 and 23516-10, respectively).

\section{$P W V$ Measurements}

Aortic PWV measurements were performed using the SphygmoCorCV MS (version 8.0; AtCor Medical, Sydney, N.S.W., Australia) by three trained individuals (C.W., M.S. and Lina Sioson). We have previously demonstrated excellent interobserver agreement [20]. In HD patients, measurements were taken immediately prior to their 'mid-week' dialysis session, i.e. on Wednesday if their schedule was Monday/Wednesday/Friday. CKD and PD patients (with an indwelling access) had these measurements performed during their routine outpatient clinic visits.

\section{Objectives and Hypothesis}

Our primary objective was to explore the relationships between the following three variables: EMPs, hemoglobin concentration and arterial stiffness (measured by PWV). We hypothesized that we would observe a positive association between EMPs and PWV, and inverse associations between hemoglobin and PWV and hemoglobin and EMPs. 
Our secondary objectives were to explore the relationship between the biomarkers measured and PWV. We hypothesized that biomarkers of inflammation and cardiovascular disease will be correlated with aortic stiffness.

We stratified the baseline data and serial EMP and PWV measurements by CKD status to highlight differences between groups.

\section{Statistics}

Demographic variables for the study cohort were summarized as follows: for categorical variables, the frequency and percentage are recorded, and differences are measured using the $\chi^{2}$ test; for normally distributed continuous variables, the mean $\pm \mathrm{SD}$ is recorded and differences are measured using a t test; for not normally distributed continuous variables, the median (interquartile range, IQR) is given, and differences are measured using the nonparametric Wilcoxon signed-rank test. Normality of the underlying distributions of the continuous variables of interest was assessed using the Shapiro-Wilk test for normality. The cohort was divided into two groups according to CKD status: those requiring a form of renal replacement therapy (RRT) and those with CKD not yet on dialysis. Associations between PWV and EMPs were assessed using Pearson's correlation coefficients. A value of $p<0.05$ was regarded as statistically significant. The statistical software programs used were SAS, version 9.1 (SAS Institute, Cary, N.C., USA) and S-PLUS 7.0.

\section{Results}

The study cohort was recruited from 500 patients on $\mathrm{HD}$ or PD, or patients with a GFR $<30 \mathrm{ml} / \mathrm{min} / 1.73 \mathrm{~m}^{2}$ at the time of enrollment. Of these, $\mathrm{n}=410$ were not eligible due to recent initiation ( $<6$ months) of RRT, recent vascular access creation ( $<3$ months), unstable hemoglobin level, known dysrhythmia or dementia. This left 90 patients eligible for enrollment, and a total of 46 patients consented to participate in the study.

Fifty-four percent of the patients were on RRT with a median dialysis vintage of 1,057 days (643-1,400), the rest were CKD subjects not yet on dialysis. Table 1 displays the baseline demographic and clinical variables stratified by CKD status. Medication use at baseline was the only difference between groups. Of note, 32 subjects (70\%) were receiving treatment with an erythropoietin-stimulating agent (ESA) at baseline. Table 2 outlines laboratory and PWV values stratified by CKD status. Hemoglobin levels were different between the CKD and dialysis group (116 vs. $122 \mathrm{~g} / \mathrm{l}, \mathrm{p}=0.06$,). In addition, patients on dialysis had a higher WBC, phosphate and parathyroid hormone level, while their albumin level was lower compared to CKD patients (table 2). CRP, IL-18 and troponin I levels were increased, and fetuin A level was decreased in the dialysis group (table 2).

\section{Baseline EMP Levels, Hemoglobin Concentration and PWV}

Patients on dialysis had quantitatively higher values of EMPs and PWV compared to CKD patients, although these differences were not statistically significant (table 2). Baseline PWV for the entire cohort is displayed in figure 1. In the overall cohort, there was no correlation between baseline PWV and EMPs measured (data not shown), baseline PWV and hemoglobin $(\mathrm{r}=-0.07, \mathrm{p}=0.66)$, or hemoglobin and EMPs measured (data not shown). When the data were stratified by CKD status, there was a positive correlation between PWV and EMP CD41-/CD144+ in the CKD patients only $(\mathrm{r}=0.54, \mathrm{p}=0.01)$, and the expected relationships between the latter two correlations, respectively, although non-significant (fig. 2). In the dialysis group, there were no significant correlations between any of these variables. 
Table 1. Baseline demographic and clinical variables according to renal disease stage

\begin{tabular}{|c|c|c|c|}
\hline Variable & $\begin{array}{l}\text { CKD } \\
(\mathrm{n}=21 ; 46 \%)\end{array}$ & $\begin{array}{l}\text { Dialysis } \\
(\mathrm{n}=25 ; 54 \%)\end{array}$ & $\begin{array}{l}\mathrm{p} \\
\text { value }\end{array}$ \\
\hline Age, years & $68 \pm 13$ & $65 \pm 13$ & 0.49 \\
\hline Males, n (\%) & $13(62)$ & $19(76)$ & 0.30 \\
\hline Caucasians, n (\%) & $14(67)$ & $12(48)$ & 0.20 \\
\hline SBP, mm Hg & $128 \pm 14$ & $128 \pm 22$ & 0.90 \\
\hline $\mathrm{DBP}, \mathrm{mm} \mathrm{Hg}$ & $73 \pm 11$ & $73 \pm 12$ & 0.98 \\
\hline Pulse pressure, $\mathrm{mm} \mathrm{Hg}$ & $55(48-61)$ & $56(41-67)$ & 0.86 \\
\hline Weight, kg & $73 \pm 14$ & $72.5 \pm 12$ & 0.84 \\
\hline Height, $\mathrm{cm}$ & $173(157-179)$ & $171(163-177)$ & 0.92 \\
\hline Body mass index & $25.2 \pm 3.0$ & $25.3 \pm 3.6$ & 0.91 \\
\hline \multicolumn{4}{|l|}{ Primary renal disease, $\mathrm{n}(\%)$} \\
\hline Diabetes & $5(24)$ & $7(29)$ & 0.66 \\
\hline Renal vascular disease & $6(28)$ & $5(21)$ & \\
\hline Hereditary causes & $2(10)$ & $1(4)$ & \\
\hline GN and vasculitis & $3(14)$ & $7(29)$ & \\
\hline Others & $4(19)$ & $4(17)$ & \\
\hline Unknown & $1(5)$ & 0 & \\
\hline \multicolumn{4}{|l|}{ Co-morbid disease, n (\%) } \\
\hline Diabetes & $4(19)$ & $8(32)$ & 0.32 \\
\hline Hypertension & $18(86)$ & $22(88)$ & 0.82 \\
\hline Dyslipidemia & 0 & $1(4)$ & 0.35 \\
\hline Current smoker & $1(5)$ & $2(8)$ & 0.66 \\
\hline Cerebral vascular disease & 0 & $2(8)$ & 0.19 \\
\hline Cardiovascular disease & $8(38)$ & $11(44)$ & 0.69 \\
\hline Peripheral vascular disease & $4(19)$ & $3(12)$ & 0.51 \\
\hline Myocardial infarction & $4(19)$ & $4(16)$ & 0.79 \\
\hline CABG & $4(19)$ & $3(12)$ & 0.51 \\
\hline Congestive heart failure & $5(24)$ & $5(20)$ & 0.76 \\
\hline Ischemic heart disease & $5(24)$ & $10(40)$ & 0.24 \\
\hline \multicolumn{4}{|l|}{ Medications, n (\%) } \\
\hline Phosphate binders & $13(62)$ & $25(100)$ & 0.0007 \\
\hline Vitamin D & $14(67)$ & $15(60)$ & 0.64 \\
\hline ACEI & $5(24)$ & $11(44)$ & 0.15 \\
\hline Angiotensin receptor blocker & $11(52)$ & $3(12)$ & 0.003 \\
\hline Statins and Ezetrol & $14(67)$ & $17(68)$ & 0.92 \\
\hline$\beta$-Blockers & $12(57)$ & $11(44)$ & 0.37 \\
\hline Calcium channel blockers & $10(48)$ & $2(8)$ & 0.002 \\
\hline Iron, $\mathrm{n}$ & $12(57)$ & $23(92)$ & 0.006 \\
\hline p.o. & 12 & 9 & 0.0005 \\
\hline i.v. & 0 & 14 & \\
\hline \multicolumn{4}{|l|}{ ESA } \\
\hline Eprex, n (\%) & $6(29)$ & $20(80)$ & 0.0005 \\
\hline Weekly dose, IU & $2,297(2,000-2,997)$ & $5,296(4,331-7,998)$ & 0.06 \\
\hline Aranesp, $\mathrm{n}(\%)$ & $2(10)$ & $4(16)$ & 0.52 \\
\hline Weekly dose, IU & $13.48 \pm 10.59$ & $19.83 \pm 9.46$ & 0.49 \\
\hline
\end{tabular}

Results are displayed as percentages where indicated, or means \pm SD and medians (IQR), depending on the underlying data distribution. $\mathrm{ACEI}=$ Angiotensin-converting enzyme inhibitor; $\mathrm{CABG}=$ coronary-artery bypass graft; GN = glomerulonephritis; SBP/DBP = systolic/diastolic blood pressure. 
Table 2. Baseline laboratory and PWV values according to renal disease stage

\begin{tabular}{lccl}
\hline Variable & $\begin{array}{l}\text { CKD } \\
(\mathrm{n}=21 ; 46 \%)\end{array}$ & $\begin{array}{l}\text { Dialysis } \\
(\mathrm{n}=25 ; 54 \%)\end{array}$ & $\begin{array}{l}\mathrm{p} \\
\text { value }\end{array}$ \\
\hline Conventional blood parameters & & & \\
WBC, $\times 10^{9} / \mathrm{l}$ & $6.5(5.3-7.5)$ & $8.1(6.5-8.7)$ & 0.03 \\
Hemoglobin, g/l & $122 \pm 11$ & $116 \pm 11$ & 0.06 \\
Calcium, mmol/1 & $2.30(2.27-2.43)$ & $2.37(2.27-2.42)$ & 0.91 \\
Phosphate, mmol/l & $1.3 \pm 0.2$ & $1.5 \pm 0.3$ & 0.02 \\
Albumin, g/l & $42(41-44)$ & $40(36-42)$ & 0.007 \\
Parathyroid hormone, pg/ml & $17(11-30)$ & $33(18-48)$ & 0.04 \\
HbA 1 , \% & $6.3 \pm 1.1$ & $6.5 \pm 1.0$ & 0.79 \\
Total cholesterol, mmol/l & $4.13 \pm 0.88$ & $3.94 \pm 1.02$ & 0.56 \\
Triglycerides, mmol/l & $1.41(0.80-1.65)$ & $1.50(1.30-2.05)$ & 0.33 \\
High-density lipoprotein, mmol/l & $1.05(0.87-1.40)$ & $0.92(0.83-1.31)$ & 0.63 \\
\hline Biomarkers & & & \\
BNP, pg/ml & $106(35-141)$ & $160(71-606)$ & 0.08 \\
CRP, mg/l & $1.7(0.6-3.3)$ & $6.0(2.4-12.5)$ & 0.003 \\
Serum IL-10, pg/ml & $10.7(7.9-13.2)$ & $14.1(11.0-18.3)$ & 0.04 \\
Serum IL-18, pg/ml & $301(251-417)$ & $374(251-584)$ & 0.11 \\
ADMA, $\mu$ mol/l & $0.62(0.57-0.68)$ & $0.65(0.59-0.74)$ & 0.56 \\
Fetuin A, g/l & $0.37(0.32-0.41)$ & $0.31(0.26-0.37)$ & 0.01 \\
Troponin I, mmol/l & $0.02(0.02-0.02)$ & $0.03(0.02-0.04)$ & 0.04 \\
\hline Microparticles, $n / \mu l$ & & & \\
CD41-/CD144+ & $34(20-84)$ & $51(29-93)$ & 0.46 \\
CD41-/CD144+/CD31+ & $7.9(4.6-13.0)$ & $11.3(4.0-15.3)$ & 0.55 \\
CD62E+ & $66(34-138)$ & $95(45-194)$ & 0.20 \\
\hline PWV, m/s & $9.9(8.5-13.1)$ & $11.4(9.7-13.1)$ & 0.22 \\
\hline
\end{tabular}

Results are displayed as means $\pm \mathrm{SD}$ or medians $(\mathrm{IQR})$, depending upon the underlying distribution of data. $\mathrm{BNP}=\mathrm{B}$-natriuretic peptide;

\section{Follow-Up EMP Levels, Hemoglobin Concentration and PWV}

At 3 and 6 months, there were no significant differences between PWV or EMP levels between groups, although the same trend to higher quantitative values was observed in the dialysis group (table 3). Likewise, a significantly lower hemoglobin level was observed in the dialysis group at 3 and 6 months. No correlation was observed between 3- or 6-month PWV and EMP values, PWV and hemoglobin, or EMPs measured and hemoglobin (data not shown).

\section{Biomarkers and PWV}

Only ADMA correlated with baseline PWV $(\mathrm{r}=0.27, \mathrm{p}=0.07)$, and this correlation remained significant at the $3-(\mathrm{r}=0.43, \mathrm{p}=0.01)$ and 6 -month measurements of $\mathrm{PWV}(\mathrm{r}=0.40$, $\mathrm{p}=0.01)$.

\section{Clinical Outcomes}

In the 6 months following the first PWV measurement, there were no clinical cardiovascular disease events recorded for the entire cohort; 1 subject died, and 2 patients underwent renal transplantation. 
Fig. 1. $\mathrm{PWV}$ in the entire cohort. Distribution of PWV is slightly skewed to the right; median $11.1 \mathrm{~m} / \mathrm{s}$, (IQR: 8.8$13.1 \mathrm{~m} / \mathrm{s})$.

Fig. 2. Relationships between hemoglobin, EMP and PWV. 3D plot demonstrating relationships between variables of interest. Correlations (Pearson) between hemoglobin, CD41-/CD144+ EMP and PWV are indicated underneath, stratified by CKD status. Note: only in the CKD (not yet on dialysis) subgroup, there is a significant correlation between EMP and PWV.
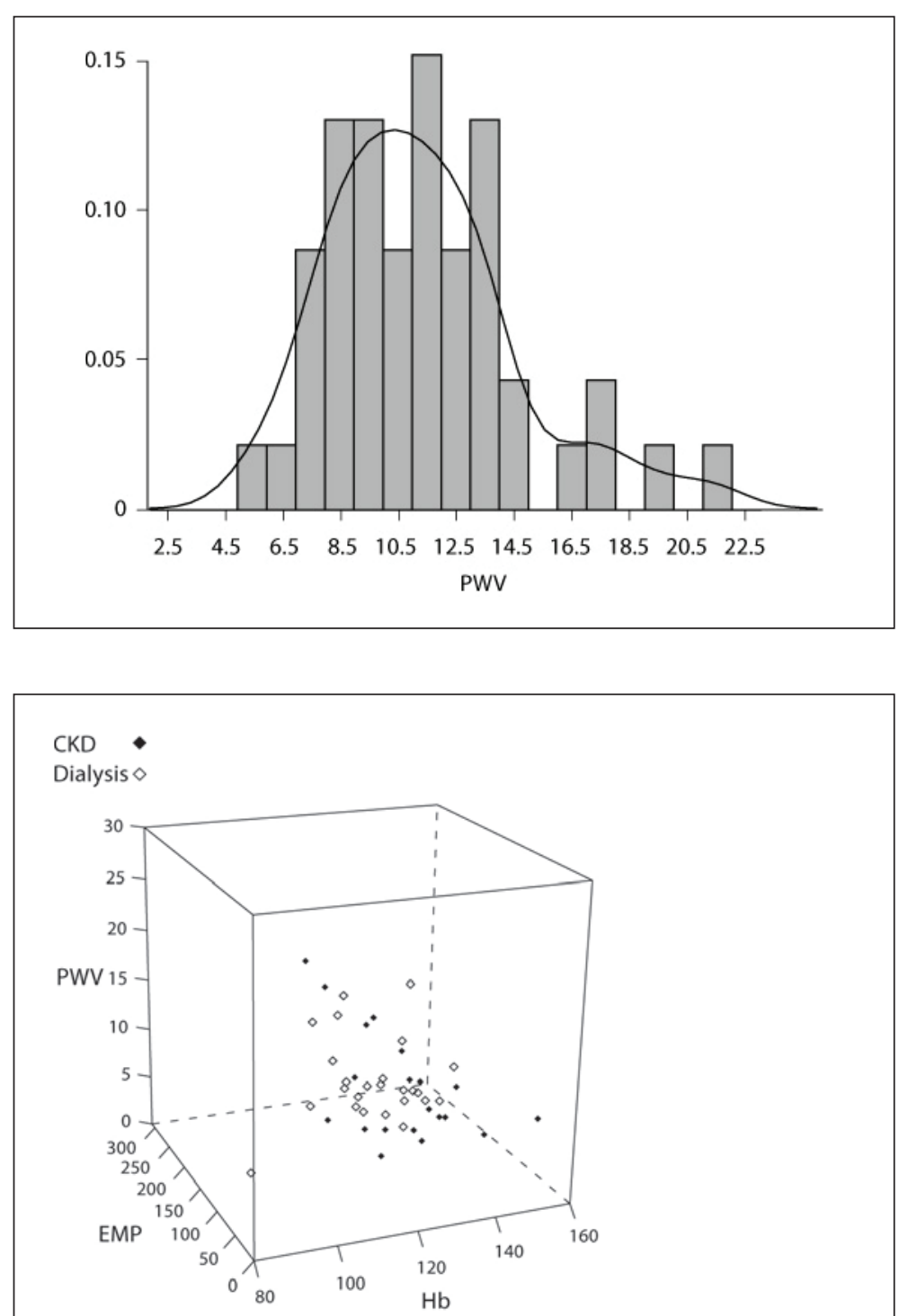

$\rho(P W V, H b)_{C K D}=-0.344(p=0.1274)$ $\rho(P W V, E M P)_{C K D}=0.543(p=0.0133)$ $\rho(\mathrm{Hb}, E M P)_{C K D}=-0.126(\mathrm{p}=0.5964)$ $\rho(P W V, E M P)_{\text {Dialysis }}=-0.091(p=0.6655)$ $\rho(\mathrm{Hb}, \mathrm{EMP})_{\text {Dialysis }}=0.221(\mathrm{p}=0.2881)$

\section{Discussion}

The purpose of this study was to explore the relationship between EMPs, hemoglobin and arterial stiffness as a preliminary step in understanding the relationship between anemia management and endothelial health in CKD patients. By stratifying the cohort by CKD status, we were able to demonstrate several differences in medication use and conventional laboratory values at baseline, and a gradation in severity of biomarkers of 'inflammation' and 'endothelial health' which persisted over time. While we were unable to find any relationship between EMPs, hemoglobin concentration and arterial stiffness in the overall cohort, there was, however, a positive correlation between PWV and EMP CD41-/CD144+ in CKD patients. 
Table 3. Follow-up data according to renal disease stage

\begin{tabular}{|c|c|c|c|}
\hline Variable & $\begin{array}{l}\text { CKD } \\
(\mathrm{n}=21 ; 46 \%)\end{array}$ & $\begin{array}{l}\text { Dialysis } \\
(\mathrm{n}=25 ; 54 \%)\end{array}$ & $\begin{array}{l}\mathrm{p} \\
\text { value }\end{array}$ \\
\hline \multicolumn{4}{|l|}{$P W V, m / s$} \\
\hline Baseline & $9.9(8.5-13.1)$ & $11.4(9.7-13.1)$ & 0.22 \\
\hline 3 months & $9.9(9.1-14.0)$ & $11.5(9.5-13.4)$ & 0.50 \\
\hline 6 months & $9.9(7.4-12.4)$ & $11.1(7.9-13.3)$ & 0.52 \\
\hline \multicolumn{4}{|c|}{ Microparticles, $n / \mu l$} \\
\hline \multicolumn{4}{|c|}{ CD41-/CD144+ } \\
\hline Baseline & $34(20-84)$ & $51(29-93)$ & 0.46 \\
\hline 3 months & $26(20-48)$ & $51(31-71)$ & 0.09 \\
\hline 6 months & $43(21-84)$ & $50(35-81)$ & 0.15 \\
\hline \multicolumn{4}{|c|}{ CD41-/CD144+/CD31+ } \\
\hline Baseline & $7.9(4.6-13.0)$ & $11.3(4.0-15.3)$ & 0.55 \\
\hline 3 months & $6.7(2.1-10.3)$ & $8.3(3.9-11.5)$ & 0.38 \\
\hline 6 months & $8.8(6.5-16.1)$ & $6.0(2.6-14.1)$ & 0.19 \\
\hline \multicolumn{4}{|l|}{ CD62E+ } \\
\hline Baseline & $66(34-138)$ & $95(45-194)$ & 0.20 \\
\hline 3 months & $66(32-94)$ & $138(71-217)$ & 0.07 \\
\hline 6 months & $81(59-159)$ & $109(70-184)$ & 0.33 \\
\hline \multicolumn{4}{|c|}{ Hemoglobin, $g / l$} \\
\hline Baseline & $122 \pm 11$ & $116 \pm 11$ & 0.06 \\
\hline 3 months & $120 \pm 9$ & $112 \pm 9$ & 0.01 \\
\hline 6 months & $124 \pm 9$ & $112 \pm 10$ & 0.0004 \\
\hline
\end{tabular}
data.

Results are displayed as means \pm SD or medians (IQR), depending on the underlying distribution of

Similar blood pressure values were observed between groups at baseline, although a higher percentage of the CKD group was prescribed anti-hypertensives (specifically angiotensin receptor blockers and calcium channel blockers). More patients in the dialysis group were prescribed ESAs, iron and phosphate binders; despite this, they had a lower mean hemoglobin concentration (116 vs. $122 \mathrm{~g} / \mathrm{l}, \mathrm{p}=0.06$ ), higher serum phosphate (1.5 vs. 1.3 $\mathrm{mmol} / \mathrm{l}, \mathrm{p}=0.02$ ) and higher intact parathyroid hormone (33 vs. $17 \mathrm{pg} / \mathrm{ml}, \mathrm{p}=0.04$ ), respectively. This observation likely relates to several factors in favor of the CKD group, including the maintenance of intrinsic erythropoietin and phosphate excretion, the absence of frequent blood loss (blood sampling/HD tubing) and lower degrees of inflammation. Consistent with this observation are the significantly higher levels of WBC, lower albumin and higher CRP, IL-10 and troponin I levels in those on dialysis compared to the CKD group. In fact, all the biomarkers assessed were quantitatively higher in those on dialysis, alluding to a greater severity of inflammation, cardiac disease and worse vascular health in this group.

PWV was higher (11.4 vs. $9.4 \mathrm{~m} / \mathrm{s}, \mathrm{p}=0.22)$ in the dialysis group, although it was not statistically significant given the small sample size. In larger studies, this $2 \mathrm{~m} / \mathrm{s}$ difference has been shown to portend higher risk and, therefore, is likely of clinical importance. The levels of the EMPs CD41-/CD144+ (specific EMP), CD41-/CD144+/CD31+ (marker of endothelial apoptosis) and CD62E+ (marker of endothelial activation) were also quantitatively higher in those on dialysis (non-significant). While EMP levels have been shown to increase with CKD severity in children, the same has not been shown in adults $[16,17]$. This may reflect the com- 
peting co-morbidities that lead to endothelial dysfunction and vascular disease in the latter group, regardless of dialysis status.

In agreement with others, we were able to demonstrate a relationship between arterial stiffness and EMPs, however only in our CKD patients $[17,18]$. Other studies have been able to describe associations between PWV, EMP and hemoglobin in patients with CKD, including those on dialysis. Boulanger et al. [21] elegantly demonstrated an inverse correlation between both EMP CD144+ (specific EMP) and CD41-/CD31+ (marker of apoptosis) and shear stress in the brachial artery related to anemia of CKD in dialysis patients. Verbeke et al. [22] demonstrated that by increasing hemoglobin from 94 to $120 \mathrm{~g} / \mathrm{l}$ with iron \pm ESA in $10 \mathrm{HD}$ patients, shear stress increased and brachial-artery stiffness decreased. Concordant with these findings, a negative association between hemoglobin concentration and arterial stiffness measured by PWV was reported in a cohort of dialysis patients, suggesting that as hemoglobin increases, endothelium health improves [3].

There may be a number of reasons for the absence of an association between hemoglobin, PWV and EMP in the present study related both to measurement techniques as well as the cohort itself. Firstly, different techniques were used to measure arterial stiffness, i.e. PWV versus brachial-artery stiffness [21,22] versus flow-mediated dilatation [18]. In addition, the patients in the current study were very well and clinically stable (low mortality rate and stable PWV and EMP levels over time) and did not represent a wide range of hemoglobin concentrations. We believe that these factors likely affected our ability to detect a relationship between hemoglobin and PWV in a relatively small number of individuals. However, we may have learned about vascular health indirectly from this cohort, given these features (i.e. that it can be maintained in the presence of clinical stability and stable hemoglobin).

Of all the biomarkers measured, only ADMA correlated with PWV-measured arterial stiffness. ADMA is an inhibitor of nitric oxide synthase and has been shown to acutely increase arterial stiffness when infused into healthy subjects [23]; it is a strong predictor of cardiovascular events and death in CKD patients [24].

There are several limitations in our study. Firstly, we studied a small, heterogeneous cohort with no control group given limitations of funding. Secondly, the difference in the timing of blood assessments, i.e. before dialysis in 'over-hydrated' HD patients versus in a 'steady state' in those on PD or with CKD may have led to differences between groups, although the impact is likely minor given that Faure et al. [16] have demonstrated that the concentration of endothelial-specific MPs is not different before and after the HD session. Furthermore, although hemoglobin was not typically drawn on the day PWV was performed, when we looked at the median hemoglobin level, it was deemed not different from hemoglobin drawn closest to the date of PWV measurement, and in such stable patients is unlikely to make a significant difference. Thirdly, our EMP levels were magnitudes below those observed in other studies. This was likely due to the fact that EMP levels were determined after a highspeed centrifugation procedure that selectively removes the smallest and lightest end of the MP spectrum detected by flow cytometry, and guaranties the removal of residual platelets. Fourthly, we acknowledge that PWV does not equal vascular disease; it measures arterial stiffness and is itself a surrogate parameter for vascular disease. As it measures a composite value of both structural and functional aspects of arterial stiffness, it may not be constant over time, nor can the 'functional' component be assessed clinically. Lastly, we did not study the impact of ESAs that are known to have both endothelium-'protective' and -'harmful' effects. Reports to date have not demonstrated an association between PWV and ESA dose or ESA responsiveness, although all are small studies $[3,21]$.

In conclusion, while others have described a physiologic link between anemia, endothelial dysfunction and arterial stiffness in CKD patients, we were not able to find this within a very stable population of CKD and dialysis patients. While our sample size is small, it is 
not significantly different from previous studies, so we would hypothesize that the stability and wellness of the population precluded demonstration of the relationships. The interaction between hemoglobin/ESA, vascular endothelium and inflammation remains complex, and given the amount of data supporting an association between these, efforts should be made to continue this line of investigation so that the relationships can be resolved.

\section{Disclosure Statement}

There is no conflict of interest.

\section{References}

1 Cunningham KS, Gotlieb AI: The role of shear stress in the pathogenesis of atherosclerosis. Lab Invest 2005;85:9-23.

2 Li YS, Haga JH, Chien S: Molecular basis of the effects of shear stress on vascular endothelial cells. J Biomech 2005;38:1949-1971.

3 Schwarz CP, Koppelstaetter C, Amann E, Mayer G: Impact of anemia on aortic pulse wave velocity in hemodialysis patients. Kidney Blood Press Res 2009;32:210-216.

4 Pfeffer MA, Burdmann EA, Chen CY, Cooper ME, de Zeeuw D, Eckardt KU, Feyzi JM, Ivanovich P, Kewalramani R, Levey AS, Lewis EF, McGill JB, McMurray JJ, Parfrey P, Parving HH, Remuzzi G, Singh AK, Solomon SD, Toto R: A trial of darbepoetin alfa in type 2 diabetes and chronic kidney disease. N Engl J Med 2009;361:2019-2032.

5 Singh AK, Szczech L, Tang KL, Barnhart H, Sapp S, Wolfson M, Reddan D: Correction of anemia with epoetin alfa in chronic kidney disease. N Engl J Med 2006;355:2085-2098.

6 Drueke TB, Locatelli F, Clyne N, Eckardt KU, Macdougall IC, Tsakiris D, Burger HU, Scherhag A: Normalization of hemoglobin level in patients with chronic kidney disease and anemia. N Engl J Med 2006;355:2071-2084.

7 Besarab A, Bolton WK, Browne JK, Egrie JC, Nissenson AR, Okamoto DM, Schwab SJ, Goodkin DA: The effects of normal as compared with low hematocrit values in patients with cardiac disease who are receiving hemodialysis and epoetin. N Engl J Med 1998;339:584-590.

8 Morris ST, McMurray JJ, Rodger RS, Jardine AG: Impaired endothelium-dependent vasodilatation in uraemia. Nephrol Dial Transplant 2000;15:1194-1200.

9 Bonetti PO, Lerman LO, Lerman A: Endothelial dysfunction: a marker of atherosclerotic risk. Arterioscler Thromb Vasc Biol 2003;23:168-175.

10 Jimenez JJ, Jy W, Mauro LM, Soderland C, Horstman LL, Ahn YS: Endothelial cells release phenotypically and quantitatively distinct microparticles in activation and apoptosis. Thromb Res 2003; 109:175-180.

11 Shantsila E: Endothelial microparticles: a universal marker of vascular health? J Hum Hypertens 2009;23:359-361.

12 Horstman LL, Jy W, Jimenez JJ, Ahn YS: Endothelial microparticles as markers of endothelial dysfunction. Front Biosci 2004;9:1118-1135.

13 Koga H, Sugiyama S, Kugiyama K, Watanabe K, Fukushima H, Tanaka T, Sakamoto T, Yoshimura M, Jinnouchi H, Ogawa H: Elevated levels of VE-cadherin-positive endothelial microparticles in patients with type 2 diabetes mellitus and coronary artery disease. J Am Coll Cardiol 2005;45:16221630 .

14 Arteaga RB, Chirinos JA, Soriano AO, Jy W, Horstman L, Jimenez JJ, Mendez A, Ferreira A, de Marchena E, Ahn YS: Endothelial microparticles and platelet and leukocyte activation in patients with the metabolic syndrome. Am J Cardiol 2006;98:70-74.

15 Garcia S, Chirinos J, Jimenez J, Del Carpio Munoz F, Canoniero M, Jy W, Horstman L, Ahn Y: Phenotypic assessment of endothelial microparticles in patients with heart failure and after heart transplantation: switch from cell activation to apoptosis. J Heart Lung Transplant 2005;24:2184-2189. 
16 Faure V, Dou L, Sabatier F, Cerini C, Sampol J, Berland Y, Brunet P, Dignat-George F: Elevation of circulating endothelial microparticles in patients with chronic renal failure. J Thromb Haemost 2006;4:566-573.

17 Dursun I, Poyrazoglu HM, Gunduz Z, Ulger H, Yykylmaz A, Dusunsel R, Patyroglu T, Gurgoze M: The relationship between circulating endothelial microparticles and arterial stiffness and atherosclerosis in children with chronic kidney disease. Nephrol Dial Transplant 2009;24:2511-2518.

18 Amabile N, Guerin AP, Leroyer A, Mallat Z, Nguyen C, Boddaert J, London GM, Tedgui A, Boulanger CM: Circulating endothelial microparticles are associated with vascular dysfunction in patients with end-stage renal failure. J Am Soc Nephrol 2005;16:3381-3388.

19 Wang JM, Su C, Wang Y, Huang YJ, Yang Z, Chen L, Wu F, Xu SY, Tao J: Elevated circulating endothelial microparticles and brachial-ankle pulse wave velocity in well-controlled hypertensive patients. J Hum Hypertens 2009;23:307-315.

20 Sigrist MK, Chiarelli G, Levin A, Romann A, Weber C: Pulse wave velocity measurements are reproducible in multiple trained observers: a short report. Nephron Clin Pract 2010;116:c60-c64.

21 Boulanger CM, Amabile N, Guerin AP, Pannier B, Leroyer AS, Mallat CN, Tedgui A, London GM: In vivo shear stress determines circulating levels of endothelial microparticles in end-stage renal disease. Hypertension 2007;49:902-908.

22 Verbeke FH, Agharazii M, Boutouyrie P, Pannier B, Guerin AP, London GM: Local shear stress and brachial artery functions in end-stage renal disease. J Am Soc Nephrol 2007;18:621-628.

23 Kielstein JT, Donnerstag F, Gasper S, Menne J, Kielstein A, Martens-Lobenhoffer J, Scalera F, Cooke JP, Fliser D, Bode-Boger SM: ADMA increases arterial stiffness and decreases cerebral blood flow in humans. Stroke 2006;37:2024-2029.

24 Zoccali C, Bode-Boger S, Mallamaci F, Benedetto F, Tripepi G, Malatino L, Cataliotti A, Bellanuova I, Fermo I, Frolich J, Boger R: Plasma concentration of asymmetrical dimethylarginine and mortality in patients with end-stage renal disease: a prospective study. Lancet 2001;358:2113-2117. 